\title{
Special Elements for Death Penalty Judgement Reasoning from the Perspective of Legal Dogmatics
}

\author{
Lei Xiaozheng \\ College of Criminal Law Science \\ Beijing Normal University \\ Beijing, China \\ leixiaozheng@163.com
}

\begin{abstract}
When out of regulation of legal dogmatics, much reasoning trial for death penalty often encounters a lot of realistic difficulties, which only takes a great amount of judicial and social costs but also causes litigation-related complaints easily so as to affect comprehensive social governance. This paper finds that, by means of judicial case studies and public interviews on streets, all sectors of society have high expectations for elements and degrees of judgement reasoning on issues involving conviction or not and immediate execution of death penalty or not. Therefore, the paper argues that, in death penalty cases, it is necessary to intensify reasoning for conviction, no punishment in doubtful cases, the unknown body and tool for criminal purpose in homicide cases, unknown sources and whereabouts of drugs with consideration of special elements for conviction and sentencing.
\end{abstract}

Keywords-Legal dogmatics; Referee documents; Reasoning elements; Death penalty cases

\section{INTRODUCTION}

The Supreme People's Court requires that each and every trial department shall firmly adhere to an objective of "Strive to make people see fairness and justice in every legal case."Judgement reasoning mainly reflects in referee document reasoning and is also an important guarantee to realize judgement reasoning. Judgement reasoning has individual case functions of resolving disputes, settling lawsuits and disputes, absorbing dissatisfaction and also has social functions of legal education and anti-crime. Status and level of referee document reasoning for death penalty cases can show in general a standard for referee document reasoning quality in countries retaining death penalty. The Supreme People's Court is gradually increasing ratio of public trial and strengthening referee document reasoning for death penalty cases so as to ensure quality of death penalty cases and control number of death sentences. For this purpose, the paper studies and analyzes the special elements in referee document reasoning for death penalty cases.

In accordance with assumptions of legal dogmatics, one of tasks of law study is to systematically summarize and conclude a standard system of the current law enforcement system and to analyze and explain structures and elements in the standard system so that some legal loopholes can be filled up. Therefore, referee documents shall include minimal elements, some of which relate to the justification of results of judgments and

The investigation project is "Study on difficulties and Resolutions for Referee Document Reasoning in Death Penalty Cases." (Register No.: 16YJC820013). rulings: statement of case proceedings, overview of proofs and arguments submitted and held by parties in action, statement of case facts, applicable legal rules, reasons in support of judgment and the final opinion and judgment of the court [1]. In a context of integration of Criminal Law, these elements in a death penalty case mainly are characterized by substantive essentials reasoning, legal proceedings reasoning, evidence use reasoning and death penalty policy reasoning.

In general, comparing with the assumption of legal dogmatics, China's referee document reasoning is based on judicial syllogism, and emphasizes substantive essentials reasoning and ignores reasoning of the rest of elements. Present situations of referee document reasoning for cases including death penalty cases often have common problems: the subject of reasoning is ambiguous, reasoning contents are insufficient, reasoning modes are rigid and full of idle talk and cliches; structures are random, and logic principles, legal principles, theoretical principles, common sense and unity and coherence in writing can not be integrated [2]. In death penalty cases, what particular difficulties does the referee document reasoning encounter? What reasoning elements need to be particularly planned or enhanced?

\section{SPECIAL REASONING FOR CONVICTION OR NOT}

Although China has unveiled a series of specific judicial explanation and conference summaries to standardize substantive parts, legal proceedings, the use of evidence and death penalty policies in death penalty cases, many difficult problems are unresolved in judicial practice and have not yet be reasoned substantially. In accordance with a survey on 180 respondents of over 18 year-old interviewed by the author's teammates in Beijing, 85.75\% is "YES" as for "Do you pay attention to death penalty cases or not and the reasons thereof". At present, the most controversial problem is how to reason convicted death sentence, and whether the most strict standard of proof is applicable? 


\section{A. Reasoning for conviction}

Comparing with ordinary criminal cases, how to define the standard of proof in death penalty cases? Particularity of standard of proof for death penalty cases is underlined in Safeguard Measures for Protection of Rights of The Condemned of the United Nations. Article 4 thereof clearly stipulates that "the accused only can be sentenced to death only in cases that crime of the accused is based on clear and convincing proof and there is no other explanation for the fact." Yet despite all that, in China, we believe that death penalty cases involve human lives but standard of proof for death penalty cases is still controversial in academic circles. For instance, some one advocates that standard of proof for death penalty cases shall be more restrictive that that of ordinary criminal cases, or standard of proof is as strict as severity of cases: as for standard proof for ordinary criminal cases, the ordinary criminal cases are directly subject to clear facts, irrefutable and sufficient evidence stipulated in the Law of Criminal Procedure, and it is very important to remove reasonable doubt on conviction; however, as for proof for death penalty cases, conviction must show determinacy, uniqueness and elimination of other possibilities except clear facts and sufficient and irrefutable evidence. Determinacy, uniqueness and elimination of other possibilities are beyond standards like elimination of reasonable doubt and more specific and explicit than "clear facts of crime, irrefutable and sufficient evidence" and "beyond question". However, are these descriptions unambiguous and pleonastic? Is request of proof of naught confession necessary for death penalty cases? It should be noted that many scholars are against the above-mentioned division, and they think that establishment of different standards is bad for judicial unity and judicial equality; some scholars even assert that fact-finding of evidence can not achieve absolute determinacy [3].

In death penalty cases, proof of all details of death penalty cases shall be clear and sufficient in facts, and an unique conclusion is unsubstantial. The key here is proof and reasoning of facts for conviction. The supreme standard of proof is applicable to core facts related to conviction, which will facilitate judicial operation and guide judicial practice. What kind of conclusion of criminal facts must be considered as uniqueness and exclusiveness? What we could give it some thought on conviction or not is that, in the case of Huugjilt in Inner Mongolia, time limit for trial period was compressed and judicial proceedings were omitted, there were only 62 days from case reporting to execution; we could learn lessons from the death sentence in its procedural reasoning: entry of appearance and a "full confession" of Huugjilt were stressed partially. For evidence analysis, only tangible evidence was submitted without response to and reasoning of retracting confession of Huugjilt and lacking of critical biological sample. We think that, because of particularity of death penalty cases, establishment of standard of proof for the whole evidence still can be based on "irrefutable, sufficient" and "beyond reasonable doubt", but more strict and specific descriptions are applicable to object of proof related to the core facts for conviction having a great stake in the cases, and that is determinacy, uniqueness and elimination of other possibilities. More precisely, we suggest that conclusion for proof of the following facts resulted from the whole evidence must be determinacy, uniqueness and elimination of other possibilities through judicial explanation provisions: the first one, there is indeed corpus of crime accused in the case; the second one, the accused commits a crime; the third one, the accused has legal criminal capacity. They are the most essential constitutive requirements related to conviction in death penalty cases and directly involve fundamental and substantive problems, such as whether a case can be treated as a criminal case and whether the accused should be convicted of a crime and sentenced. The accused can not be convicted of a crime if any one of three facts does not meet the above-mentioned requirements. The above-mentioned requirements will make proof of death penalty cases more strict than that of ordinary criminal cases, which facilitates preventing occurrence of cases in which people were unjustly sentenced on facts for conviction.

\section{B. Reasoning for no punishment in doubtful cases}

In modern criminal justice, no punishment in doubtful cases is a key requirement for presumption of innocence principle. In death penalty cases, it is an inevitable requirement for upholding spirit of government by law to adhere to no punishment in doubtful cases and also a key to enforce trialoriented principle. However, why no punishment in doubtful cases is violated in judicial practice of some criminal cases? We found that, a judgement thought that "flexible verdicts" and "no punishment in doubtful cases" do not contradict each other still exists in judicial practice of the Supreme People's Court, "no punishment in doubtful cases" is pragmatic in judgment of crime and non-crime, and "flexible verdicts" is always restricted to criteria for sentencing. We think that meaning of "flexible verdicts" in judicial practice has been expanded and it seems to be in favour of the accused, however, it makes against the accused substantially: "suspected" cases which should be out of guilty are settled by "tolerance" on sentencing. In recent years, from a perspective of progress in judicial reform, policymakers have realized that, when verdict evidence in death penalty cases is insufficient, the principle of no punishment in doubtful cases must be strictly followed to give a non-crime judgment because of greater social influence and sever harmfulness of death penalty cases and severity of criminal law. From some unjustified cases with "flexible verdicts", such as a corrected case of SHE Xianglin, these cases shall not be treated as constitution of a crime in its previous trial proceedings. [4]

We think that, judicial explanation shall further explicitly stipulate that, if cases without sufficient inculpatory evidence after strict evidence review and judgment, the accused shall be acquitted due to insufficient evidence and false accusation, and death penalty with a two-year reprieve, life imprisonment and set term of imprisonment shall not be made by concession. From a perspective of regulating reasoning, the accused in cases with unclear facts and insufficient evidence shall be acquitted. Then it can be said that, "flexible verdicts" existing in judgment of suspected death penalty cases is actually to avoid "delinquency" in aspects of collecting inculpatory evidence by the state judicial organs. The true purpose of the "flexible verdicts" is "the presumption of guilt", which directly violates the bottom line for the character of prudential and normativity of judicial power in law government by modern criminal proceedings. And death penalty cases have more 
trouble. Suspected death penalty cases that should be out of guilty are sentenced to death penalty with a two-year reprieve, life imprisonment, set term of imprisonment, which seems to avoid immediate execution of death (or generally speaking, "save a life"), but actually deprives the accused of the right to be innocent. Also, in some cases, real criminals may be indulged, which is a hidden trouble for leading to unjustified cases.

\section{SPECIAL REASONING FOR REGULATING SENTENCING}

Conviction reasoning and sentencing reasoning are different in referee document reasoning. In death penalty cases, the accused in some cases can constitute a crime combining with evidence of the whole cases, however, judgment of immediate execution of death penalty is always "in a dilemma". The primary reasons are that, absence of key evidence will result important facts of a case in an ambiguity condition and unjustified cases may be caused by judgment without careful consideration, particularly in death penalty cases of great severity. The Absence of key evidence often strikes to homicide and drugs cases related to violent crimes. Article 6 in Opinions on Working Mechanism about Establishing and Improving Precaution of Unjustified Criminal Cases stipulates that, "Under condition of irrefutable and sufficient evidence, if the evidence influencing sentencing is in reasonable doubt, treatment in favor of the accused shall be made on sentencing." Whereby, an ambiguous description of "in reasonable doubt" is used for identification standard of sentencing evidence. For this reason, intensive reasoning shall be used to make more explanation.

In recent years, many unjustified cases are made under condition of survival of "the decedent" or absence of tool for criminal purpose in judicial practice. In accordance with a survey on 180 respondents of over 18 year-old interviewed by the author's teammates in Beijing, the public all gives "YES" to "Whether death penalty sentencing is fair enough" is underlined in referee documents of death penalty cases, as the same as "Whether there is extorting confession by torture" and "Defense opinions are responded or not." Based on standardized sentencing, we suggest that, three special situations are badly in need of sufficient reasoning in line with principle of "in favor of the accused" if the accused is convicted of a crime but can not be sentenced to death.

\section{A. Unknown body in homicide cases}

The first situation is that the body can not be found or unidentified in homicide cases and there is no reasonable explanation. The body is key evidence in homicide cases. Situations, such as "survival of the decedent" or "nonconformity of the decedent and the victim", can be eradicated through identification between the body and the decedent. In judicial practice, it is an actual possibility that the body is not found or can not be identified on some occasions. For instance, the body is in the sea, the victim is pushed off a plane from a high altitude without a parachute, or the body is treated by professional chemical process, etc. The accused can be sentenced to death if the victim is exact the "body" in the case based on other evidence and with conformity of the experience rule. For example, the criminal pushes the victim off a plane from a high altitude in public. However, the accused can not be sentenced to death to avoid unjustified cases if the body is not found or unidentified without any reasonable explanation. The such cases shall be free of sentence of death and more possibilities are given in the future.

\section{B. Unclear tool for criminal purpose in homicide cases}

The second situation is that, tool for criminal purpose resulting in death is not found in a homicide case using knives and sticks to cause death and also reasonable explanation can not be given. In death penalty cases that knives and sticks are used to cause death, whether the knives and sticks can be found is closely related to physical features, disposal methods and locations. The accused can be sentenced to death if tool for criminal purpose is indeed used combining other evidence and also reasonable explanation is given. Inducing a person to make a confession or confession under directions shall be prevented when tool for criminal purpose resulting death is not found and also reasonable explanation can not be given; death penalty can not be imposed on the case, and the primary purpose is to avoid unjustified cases.

\section{Unclear Sources and whereabouts of drugs}

The third situation is that, in drug cases, sources and whereabouts of drugs can not be verified despite other evidence of the accused confession. Due to China's tough stance for cracking down drug crime, and also because determination procedure of drug crime relates to informant, technical investigation and evaluation, the principle of evidentiary adjudication is more important in trial process to determine death penalty in drug crime. Drugs, sources and whereabouts are very critical for evidence determining drug crime. In practice, drugs can not be seized, and drug cases in which sources and whereabouts of drugs can not be verified easily happen, despite other evidence of the accused confession, the suspicions of "false accusation", "extorting a confession by torture" and "illegal inductive investigation" can not be ruled out. With adherence to "in favor of the accused", it is regulated that the accused in the such cases can not be sentenced to death, which also is a system guarantee for everyone to have a peace travel and guard against drug possession by being framed.

\section{CONCLUSION}

Sir William Wade once pointed that "The reason to make determination is the requirement of sense of justice of common people, and it is also a healthy commandment for the people having right to exercise power over others." [5] In countries retaining death penalty, substantive reasoning of referee documents can be employed to contain power despotism and abuse in criminal justice. Proof for conviction or not and sentencing to death or not requires reasoning to be "qualified" and "adequate", which means the stricter the legal argument, the sufficient the reasoning, and the higher the judicial civilization index. Of course, reasoning methods shall be optimized for reasoning of problems like conviction, sentencing and their proof in death penalty cases. For this aspect, the Supreme People's Court can unveil relevant guiding cases and judicial operation guides based on particularities of 
reasoning so as to make a change from formal reasoning to substantive reasoning.

\section{REFERENCES}

[1] Wang Guidong, Written Judgment Structure and Its Reasoning Functions, Law Theory, 2008 (8).

[2] Xi Wei, Zhu Minmin, Difficulties and Resolutions for Elimination Reasoning of Illegal Evidence in Criminal Judgement, Academic Forum, 2015 (7).

[3] Zhang Baosheng, Facts, Evidence and Facts Fining, Social Sciences in China, 2017 (4)

[4] Xu Jun, No Leeway in Pursuing Fairness, Justice of China, 2016 (11).

[5] Wade, William. Executive Law (Xu Bingyi, Trans.). Beijing: Encyclopedia of China Publishing House, 1997, p193. 